\title{
Citrus limon L Burmf leaves from North Eastern India : A source of Amino acids
}

\section{Elija Khatiwora}

Department of chemistry, Y.M. College, Bharati Vidyapeeth Deemed University, Pune-38, India.

\section{ABSTRACT}

Identification of amino acids from air shade dried powered material of Citrus limon L Burmf (Assam lemon) leaves was carried out in this experiment. Paper chromatographic technique was used for the qualitative determination of amino acids with different mobile phases. Specific amino acids were detected in specific mobile phases. The obtained amino acids were identified by comparing with standard amino acids. Total nine amino acids were detected from of Citrus limon L Burmf leaves. Two mobile phases were found suitable for detection of amino acids present in the leaves of citrus limon L Burmf.
\end{abstract}

Keyword: Citrus limon, Paper chromatography, Amino acids.

Article Info: Received 10 July 2019; $\quad$ Review Completed 21 Aug 2019; $\quad$ Accepted 24 Aug 2019; Available online 30 Aug 2019

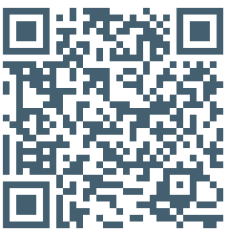

Cite this article as:

Khatiwora E, Citrus limon L Burmf leaves from North Eastern India : A source of Amino acids, Journal of Drug Delivery and Therapeutics. 2019; 9(4-A):269-270 http://dx.doi.org/10.22270/jddt.v9i4-A.3468

*Address for Correspondence:

Elija Khatiwora, Department of chemistry, Y.M. College, Bharati Vidyapeeth Deemed University, Pune-38, India.

\section{INTRODUCTION}

Citrus limon L Burmf belongs to family rutaceae. It is also known as Assam lemon and one of the most important crops of Assam and other parts of north eastern region. Fruit is widely used for culinary, beverages, industrial and medicinal uses. The fruits are sour, rich in vitamin $\mathrm{C}$ which strengthens the immune system, acts as an antioxidant and protects cells from radical damage 1 . Infusion of the bark or peel of the fruits is given to relive colic. It is used as antiseptic, antibiotic and antiviral. Anthelmintic activity Citrus limon were investigated 2,3,4. Comparative study of antioxidants changes including total flavonoid, total phenol and total antioxidant capacity of Citrus limon fruits grown at the north of Iran were examined 5 . Antimicrobial activity of juice in ripens and unripe forms of Citrus limon were studied 6. Anthemintic activity of citrus limon L Burmf extracts was published in author's previous work ${ }^{7}$.

Amino acids are the building blocks of our body. A large proportion of our cells, mussels, and tissue are made up of amino acids. They carry out many important bodily functions such as giving cells their structures. Amino acids are essential for healing wounds and repairing tissue especially in the mussels, bones, skin and hair. Considering the fact, investigation of amino acids from citrus limon $\mathrm{L}$ Burmf leaves has been carried out. As per the available reports this is the first study of qualitative determination of amino acids from citrus limon L Burmf leaves collected from Biswanath district, Assam, India.

\section{MATERIAL AND METHOD}

The plant material was collected from Naduar area, Biswanath district, Assam, India.

The plant was authenticated at Department of Life Sciences, Dibrugarh University, Assam, India.

Whatman filter paper no.1 was used for paper chromatography. Amino acid kit (CHH laboratory reagent) was used for standard amino acids. Air shade dried powdered material was used for extract preparation. Three extracts were prepared by using weighed quantity of powder in known volume of water, $9 \%(\mathrm{w} / \mathrm{v})$ aqueous sodium chloride solution and ethanol. Extraction procedure was repeated 3 times using chloroform to remove chlorophyll. The chlorophyll layer was separated and remaining part was used for amino acid analysis ${ }^{8}$. Nine amino acids were detected and identified from citrus limon leaves after spraying ninhydrin spray. Following mobile phases were tried to screen out the best mobile phase for separating the amino acids present in the citrus limon leaves by paper chromatographic technique: (i) phenol: water (1:1), (ii) water: butanol: acetic acid (5: $4: 1)$, (iii) $n$ hexane : n- butanol : methanol : acetic acid: water ( $0.5: 3: 1: 2: 3.5)$, (iv) n- butanol : acetone : water $(1: 3: 2),(v) n-$ butanol : 
acetone : water $(1: 3: 1)$, (vi) n-propanol : ammonia ( $7: 3)$, (vii) $n$ - butanol :ethanol : water : pyridine $(2: 0.5: 1: 1.5)$, (viii) n- butanol :ethanol : water : pyridine $(3: 2: 3: 2)$, (ix) pyridine :ammonia $(7: 3)$.

Out of these mobile phase, $\mathrm{n}$ - butanol : ethanol : water : pyridine $(3: 2: 3: 2)$ and pyridine : ammonia $(7: 3)$ were found suitable for leaves. The experimental extracts were spotted on the chromatographic paper along with the standard samples. The mobile phase was allowed to run to a certain height and the chromatogram was dried at room temperature. Ninhydrin solution was sprayed on the paper and again dried at room temperature. The $\mathrm{R}_{\mathrm{f}}$ values of the amino acids of the experimental samples were determined and compared with the standard. Table.1 below enlists the amino acids present in leaves of the plant.

\section{RESULT AND DISCUSSION}

The presence of nine amino acids from citrus limon leaves were detected in mobile phase n- butanol: ethanol: water: pyridine (3:2:3:2). These were L - ornithine Monohydrochloride, L- arginine Monohydrochloride, L Histidine monohydrochloride, DL - Aspartic acid, L - Lysine Monohydrochloride, Glycine, L- Hydroxy proline, DL- alanine and DL- Threonine. These amino acids were identified by comparing the $\mathrm{R}_{\mathrm{f}}$ value with the standard. These amino acids play important role in cell metabolism.

Table 1: Amino acids detected from Citrus limon L Burmf leaves.

Mobile phase: $n$ - butanol: ethanol : water : pyridine $(3: 2: 3: 2)$.

\begin{tabular}{|l|l|l|}
\hline Name of amino acids & Rf values for standard amino acid & Rf values for amino acids of the peel \\
\hline L-ornithine Monohydrochloride, & 0.136 & 0.130 \\
\hline L-arginine Monohydrochloride, & 0.181 & 0.191 \\
\hline L-Histidine monohydrochloride & 0.327 & 0.332 \\
\hline DL- Aspartic acid, & 0.363 & 0.363 \\
\hline L-Lysine Monohydrochloride, & 0.445 & 0.450 \\
\hline Glycine & 0.554 & 0.547 \\
\hline L- Hydroxy proline & 0.645 & 0.636 \\
\hline DL- alanine. & 0.690 & 0.690 \\
\hline DL - Threonine & 0.663 & 0.672 \\
\hline
\end{tabular}

\section{CONCLUSION}

Citrus limon L Burmf leaves extracts contain several amino acids. It also showed the presence of other secondary metabolites and biological activity which were mentioned in author's previous work. So, it can be concluded that Citrus limon L Burmf leaves can be evaluated as a potential source of natural bioactive chemicals. The bioactivity data offers a scientific proof for the traditional use of the plant.

\section{ACKNOWLEDGEMENT}

The author is thankful to the principal, Y.M. College, Bharati Vidyapeeth Deemed University, Pune- 38 , India for providing the necessary support to carry out this work.

\section{REFERENCES}

[1] http://en. wikipedia.org/wiki/lemon.

[2] The citrus plant, In: citrus. Ciba-Geigy Agrochemicals Tech. Monogr.4. Ciba-Geigy Ltd., Basle, Switzerland, 1975, p.6-13
[3] Hesperides. A history of the culture and use of Citrus. Fruits, p.371. John Bale, Sons and Curnow, 1938, London, England.

[4] Munne S, Parwate D, Ingle V, NagpurkarV, Evaluation of the anthelmintic activity of citrus limon juice sacs, Int JPharma Professional's Research, 2011, 2(2) .

[5] Mohammadian MA, Mobram ZI, Sajedi RH, Bioactive compounds and antioxidant capacities in the flavedo tissue of two citrus cultivars under low temperature, Braz J Plant Physiol, 2011, 23(3), 203-208.

[6] Sarmah N, Kumari S, Comparative study of antibacterial activity of ripen and unripen Indigenous Citrus union of Assam, India, Int J Advancements in Research \& Technology, 2013, 2(9), 25-31.

[7] Elija Khatiwora, Citrus limon L Burmf leaves from north estern India : A potential source of anthelmintic agent against Eicinia foetida, J DDT, 2018, 8 (3) ), 55- 57.

[8] J. Gasparic, J. Churacek, Laboratory Handbookof Paper and Thin layer Chromatography, Ellise - Horwood Ltd., Sussex, England, pg 16,1978 . 